\title{
Estimativa da biomassa de raizes de duas espécies de Cecropia e sua relação com a associação ou não das plantas a formigas $\left(^{*}\right)$
}

\author{
Flávio Jesus Luizão ("*) \\ Rita Maria Fortunato de Carvalho $(n t *)$
}

\begin{abstract}
Resumo
Este trabalho propõe a hipótese de que as formigas associadas com várias espécies do gênero Cecropia, além do outro possivel papel como agentes alelopáticos (sensu Janzen, 1969), estariam concentrando nutrientes para as plantas. Esta hipótose foi testada pela comparação do desenvolvimento da biomassa radicular, através da razão peso fresco das raizes/peso fresco do caule, de uma espécie associada a formigas, C. concolor Willdenow, e uma espécie não-associada a formigas, C. sciadophylla Martius. Os resultados indicam que C. concolor tem uma razão média raízes/caule de 0,27 $(n=5)$, enquanto em C. sciadophylla a mesma razão é de $0,50(n=5)$, uma diferença significativa ao nivel de $5 \%$. Esta tendência, portanto, corrobora a hipótese inicial.
\end{abstract}

\section{INTRODUÇÃO}

$\mathrm{Na}$ Amazônia brasileira, existem mais de quinze espécies de imbaúbas (gênero Cecropia), constituindo-se em um grupo de plantas colonizadoras de grande sucesso e vasta distribuição, ocorrendo em número elevado nas áreas de clareiras e outras áreas abertas (tais como as margens de estradas), ou de vegetaçāo secundária (Berg, 1978). A grande maioria destas espécies encontra-se associada a formigas "taxis" (formigas agressivas, principalmente do gênero Azteca), sendo tal associação conhecida há longo tempo, como demonstram breves descrições da mesma feitas, já no século XVII por Marcgravius, Piso e Ray apud Wheeler (1942). Embora somente dois séculos mais tarde tenha aparecido um novo trabalho sobre o assunto (Belt, 1874), daí até o presente muitos outros foram feitos, mostrando a associação de muitas espécies de Cecropia com formigas, as quais se abrigam e nidificam nos caules das plantas, delas retirando também os seus alimentos (Wheeler, 1942). As formigas retiram o seu alimento, rico em glicogênio semelhante ao animal (Rickson, 1971), dos corpúsculos Müllerianos existentes entre os triquíolos, que são tufos pardos de pêlos que podem ocorrer na base dos pecíolos de todas as espécies de Cecropia, com exceçãc da Cecropia sciadophylla (Berg, 1978). A árvore tem o tronco oco que serve como local dos ninhos e tolera, ainda, uma constante perda de energia através de homópteros que são mantidos, no interior dos troncos, pelas formigas (Wheeler, 1942). As vantagens são, portanto, muito óbvias para as formigas, mas, para as imbaúbas são ainda muito discutíveis e, aparentemente, as hipóteses usuais não chegam a justificar plenamente o "mutualismo" para a planta: Müller (1880) e Schimper (1888) postularam que as formigas impediriam, ou pelo menos reduziriam, o ataque de herbívoros sobre as plantas, principalmente o das formigas cortadeiras; Janzen (1969, 1973) afirma que as formigas reduzem o crescimento das ervas trepadeiras sobre as imbaúbas, facilitando, assim, a obtenção e manutenção, pela imbaúba, de uma posição emergente no dossel da vegetação secundária, o que seria uma vantagem seletiva desta planta em relação às outras espécies. Estudos realizados indicam que tanto uma coisa como outra pode ocorrer, porém as vantagens da Cecropia ainda seriam desproporcionais às das formigas e também muitas imbaúbas associadas a formigas foram encontradas bastante atacadas por herbívoros (principalmente pela "preguiça", na região amazônica) e com grande quantidade de ervas trepadeiras, o que pode dar a idéia de que as

(*) - Trabalho desenvolvido como "Projeto de um dia" durante o desenrolar da disciplina Problemas Especiais em Biologia Tropical - Ecologia de Campo I (Convênio INPA/UNICAMP), de julho a agosto de 1979.

(*) - Instituto Nacional de Pesquisas da Amazônia. Curso de Pós-Graduação em Ecologia. Bolsista do CNPq.

$(* * *)$ - Curso de Pós-Graduação em Botânica. UNICAMP, Campinas (SP). 
formigas desempenham outras formas de proteção à Cecropia, tal como a proteção contra fungos, já que os triquíolos colhidos pelas formigas correspondem a uma diminuição de substratos favoráveis a eles (Berg, 1978). Aiém disso, as formigas poderiam também fornecer às imbaúbas um substancial teor de alguns nutrientes essenciais, principalmente nitrogênio, fósforo e cálcio, encontrados nas fezes que ficam nos ninhos localizados no interior do tronco oco (Stark, 1970). Num dos testes realizados sobre a fixação de nitrogênio por formigas de Cecropia, realmente foram encontrados indícios positivos (Sylvester-Bradley, comunicação pessoal) .

Baseando-se no postulado referente ao fornecimento de nutrientes às plantas (Stark, 1970), procurou-se verificar o desenvolvimento do sistema radicular de duas espécies diferentes de Cecropia de uma mesma clareira artificial, sendo uma espécie associada a formigas (C. concolor Willdenow) e a outra não ( $C$. sciadophylla Martius), supondo-se que, se a espécie associada a formigas recebe alguns nutrientes essenciais concentrados nas fezes das formigas, diretamente, e não apenas do solo, por meio das raízes, então deveria apresentar um sistema radicular menos desenvolvido, em relação à parte aérea da planta, do que a espécie não associada a formigas, que precisa retirar todos os nutrientes necessários apenas do solo.

\section{MATERIAL E MÉTODOS}

Foram selecionadas cinco árvores de $\mathrm{Ce}$ cropia sciadophylla Martius, 1841, sem formigas, e outras cinco de Cecropia concolor Willdenow, 1806, com formigas, apresentando alturas (entre 1,50 e $6,0 \mathrm{~m}$ ) e biomassas aéreas semelhantes, uma a uma, e encontradas numa mesma clareira artificial, situada nas proximidades dos alojamentos do INPA, na Estação Experimental de Silvicultura Tropical, km 44 da rodovia BR-174 (Estrada Manaus-Caracarai). As 10 árvores selecionadas foram cortadas, os troncos cortados e pesados, as folhas contadas e pesadas e as raizes vivas foram arrancadas totalmente (ou estimado o restante no solo, quando havia sobras), lim- pas e pesadas. Para o corte das árvores e separação dos seus componentes aéreos foram usados terçados grandes e, para a extração das raízes, usou-se uma enxada apropriada para cavar num raio de aproximadamente $70 \mathrm{~cm}$ ao redor da base do tronco e a uma profundidade de $30 \mathrm{~cm}$, completancio-se a retirada das raízes com as mãos. Os componentes das árvores. depois de cortados e separados, eram colocados em saco plástico de peso previamente conhecido e depois pesados com auxílio de dois dinamômetros de mola fixados em traves de madeira colocadas na própria área de coleta. As medidas da altura das árvores foram feitas com o usc de trenas metálicas. A partir dos dados obtidos no campo, foram calculadas a biomassa aérea, a biomassa total e a razão entre o peso fresco das raízes e do caule de cada planta. A diferença entre as médias destas razões foram analisadas estatisticamente por meio de uma análise de variância.

\section{Resultados E discussão}

Os resultados obtidos se encontram sumariados na tabela $\mathrm{I}$, juntamente com as médias, desvios padrão e variâncias para a razão raízes/caule. A análise de variância (ANOVA) efetuada para verificar se a diferença entre as médias da razão peso fresco das raízes/peso fresco do caule para as duas espécies estudadas era significativa, mostrou o seguinte resultado :

$$
\mathrm{F}_{\mathrm{s}}=5,59 \quad \mathrm{~F}_{0,05[1 ; 8]}=5,32
$$

sendo, portanto, a diferença estatisticamente significativa ao nível de $5 \%$.

Como termo de comparação para as duas espécies estudadas, preferiu-se o peso fresco do caule ao invés do peso fresco de toda a parte aérea porque ao menos uma das árvores estudadas, a $C$. concolor número 5 , apresentava quantidade e biomassa de folhas muito reduzidas em relação às outras árvores selecionadas e aos seus demais componentes (caules e raízes) e o mesmo poderia ocorrer em outras árvores, face a ataques de pragas ou outras causas, o que influenciaria no tratamento estatístico de um número pequeno de amostras, como no caso presente. 


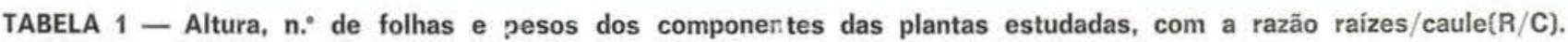

\begin{tabular}{|c|c|c|c|c|c|c|c|c|c|c|c|c|c|c|c|}
\hline \multicolumn{8}{|c|}{ C. concolor } & \multicolumn{8}{|c|}{ C. sciadophylla } \\
\hline \multirow{2}{*}{$\begin{array}{l}\text { Alt. } \\
\text { (m) }\end{array}$} & \multirow{2}{*}{$\begin{array}{l}\text { N.O de } \\
\text { folhas }\end{array}$} & \multicolumn{5}{|c|}{ Peso fresco (em $\mathbf{k g})$} & \multirow[b]{2}{*}{$\mathrm{n} / \mathrm{c}$} & \multirow[b]{2}{*}{$\begin{array}{l}\text { Alt. } \\
\text { (m) }\end{array}$} & \multirow{2}{*}{$\begin{array}{l}\text { N.० de } \\
\text { folhas }\end{array}$} & \multicolumn{5}{|c|}{ Peso fresco (em $\mathbf{k g})$} & \multirow[b]{2}{*}{$\mathrm{B} / \mathrm{C}$} \\
\hline & & Raizes & Folhas & Coule & $\begin{array}{l}\text { Parte } \\
\text { aérea }\end{array}$ & $\begin{array}{c}\text { Biomassa } \\
\text { total }\end{array}$ & & & & Raizes & Folhas & caule & $\begin{array}{l}\text { Parte } \\
\text { aérea }\end{array}$ & $\begin{array}{c}\text { Biomassa } \\
\text { total }\end{array}$ & \\
\hline 4,80 & 53 & 2,288 & 1,150 & 6,750 & 7,900 & 10,188 & 0,34 & 5,05 & 16 & 8,880 & 3,200 & 6.410 & 9,610 & 12,490 & 0.45 \\
\hline 5,80 & 9 & 0,582 & 0,430 & 3,100 & 3,530 & 4,112 & 0,19 & 3,24 & 14 & 0,949 & 1,500 & 1,950 & 3.450 & 4,399 & 0.49 \\
\hline 2,70 & 8 & 0,131 & 0,205 & 0,715 & 0,920 & 1,051 & 0.18 & 2,61 & 11 & 0,420 & 0,900 & 1,225 & 2,125 & 2,545 & 0,34 \\
\hline 4,10 & 8 & 0,347 & 0,280 & 1,500 & 1,780 & 2,127 & 0,23 & 2,65 & 15 & 0,444 & 1,200 & 1,100 & 2,300 & 2.744 & 0.40 \\
\hline 3,28 & 7 & 0,352 & 0,155 & 0,845 & 1,000 & 1,352 & 0,42 & 1,56 & 14 & 0,306 & 0,705 & 0,365 & 1,070 & 1,376 & 0,84 \\
\hline $\bar{x}$ & & & & & & & & 0,27 & & & & & & & 0.50 \\
\hline s & & & & & & & & 0,10 & & & & & & & 0.19 \\
\hline$s^{2}$ & & & & & & & & 0,010 & & & & & & & 0.037 \\
\hline
\end{tabular}

$0,05>P>0,01$

O resultado da ANOVA aplicada, mostrando ser significativamente maior a razão raízes/ caule da $C$. sciadophylla em relação à $C$. concolor, pode ser facilmente observado, no desenrolar do trabalho de campo, onde se notava, nas árvores da primeira espécie, a presença de raízes mais espessas, mais ramificadas (em gerai, superficialmente), mais numerosas $e$ com comprimentos até mesmo superiores à altura da própria planta. Desta forma, foram obtidas evidências de que as imbaúbas não associadas a formigas apresentam proporcionalmente uma maior biomassa de raízes, possivelmente como uma compensação pelo fato de elas terem que retirar todos os seus nutrientes necessários do próprio solo, enquanto que as imbaúbas associadas a formigas receberiam parte dos nutrientes essenciais das próprias formigas, o que justificaria o menor desenvolvimento de suas raizes. No entanto, apesar de terem sido obtidas diferenças significativas, inclusive estatisticamente, neste estudo, deve-se ressaivar que foram utilizadas poucas amostras por espécie e foram testadas apenas duas espécies de Cecropia, escolhidas ao acaso. Para obtenção de conclusões mais amplas, julga-se necessária a realização de ou- tros experimentos, com mais repetições, maior número de amostras por espécie e com outras espécies de Cecropia associadas a formigas. bem como a inclusão de outros parâmetros no estudo.

\section{SUMMARY}

This paper proposes the hypothecis that ants associated with several species of Cecropia, besides their other possible role as allelopathic agents (sensu Janzen, 1969), are concentrating nutrients for the plants. This hypothesis was tested by comparing the development of the biomass of the root system through the ratio fresh root biomass/fresh stem biomass of an ant-associated species, C. concolor Willdenow, and an ant-free species, C. sciadophylla Martius. The results indicate that C. concolor has a mean ratio root/stem of 0,27 $(n=5)$, whereas in C. sciadophylla the same ratio is $0,50(n=5)$, a difference significant at the $5 \%$ level. This trend, therefore, corroborates the initial hypothesis.

\section{REFERÊNCIAS BIBLIOGRÁFICAS}

BELT, T.

1874 - The naturalist in Nicaragua. Bumpas, London. $403 \mathrm{p}$.

BERG, C.C.

1978 - Espécies de Cecropia da Amazĉnia Brasilei ra. Acta Amazonica, 8 (2): 149-182. 
JANZEN, D.H.

1969 - Allelopathy by Myrmecophytes: the ant Azteca as an allelopathic agent of Cecropia. Ecology, 50 (1): 147-153

1973 - Dissolution of Mutualism between Cecropia and its Azteca ants. Biotropica, 5 (1): 15-28.

MÜLLER, F.

1880 - Die Imbauba und ihre Beschützer. Kosmos 8: $109-116$.

RiCKSON, F.R.

1971 - Glycogen plastids in Müllerian body cels of Cecropia peltata, a higher green plant. Science N.Y. 173: 344-347 (N. 3994).
SCHIMPER, A.F.W.

1888 - Die Wechselbeziehungen zwischen Pfianzen und Ameisen im tropischen Amerika. Bot. Mitteil. aus den Tropen. Jena I: 1-95.

STARK, N.

1970 - The Nutrient Content of Plants and Soils from Brazil and Surinam. Biotropica 2 (1): 51-60.

WHEELER, W.M

1942 - Studies of Neotropical Ant-Plants and their Ants. Bulletin of the Museum of Compara. tive Zoology at Harvard College Cambridge, 262 p.

(Aceito para publicação em 26/11/80) 